допустимые концентрации (ПДК) загрязняющих веществ в атмосферном воздухе населенных мест» [Электронный pecypc] // http:/garant.ru/products/ipo/ prime/doc/70592956.

11. Обзор состояния и загрязнения окружающей среды на территории деятельности Саратовского ЦГМС - филиала ФГБУ «Приволжское УГМС» за 2015 г. [Электронный pecypc] // http://pogoda-sv.ru/ docs/ecology_info/ecology_review/sar_2015.pdf.

12. Ежегодник Состояние загрязнения атмосферы в городах на территории России за 2014 г. ФГБУ «Главная геофизическая обсерватория им. А.И. Воейкова», Росгидромет. СПб, 2015 г. 288 с.

13. Сысоева Т.И., Карпова Л.С., Безуглая Э.Ю Оценка влияния загрязнения атмосферного воздуха формальдегидом на суммарную заболеваемость гриппом и ОРВИ в 29 городах России // Ежемесячный научно-практический бюллетень «Здоровье населения и среда обитания». № 3 (264), март 2015. С. 45-48.

14. World Health Organization. Air Quality Guidelines global update 2005. Report on working group meeting [Электронный pecypc] // http://euro.who.int/_data/ assets/pdf_file/0008/147851/E87950.pdf.

15. Амреева К.Е., Омирбаева С.М. Оценка риска влияния техногенного загрязнения атмосферного воздуха на здоровье населения в условиях центрального Казахстана [Электронный ресурс] // Современные проблемы науки и образования. 2012. № 6. http://www.science-education.ru/ru/article/view?id=7452.

16. Хотько Н.И., Дмитриев А.П. Санитарное состояние атмосферного воздуха и здоровье населения // Известия высших учебных заведений. Поволжский регион. Медицинские науки. № 2 (22). 2012. С. 125-134.

17. Молодцева А.В. Экологическая оценка воздействия загрязнения атмосферного воздуха на здоровье населения (на примере Ивановской области): автореф. дис. ... канд. биол. наук. Владимир, 2013. 24 с.

18. Какарека С.В., Ашурко Ю.Г. Анализ и оценка источников выбросов формальдегида в атмосферный воздух на территории Беларуси // Природопользование. Вып. 21., 2012. С. 75-82.

19. Доклад «О состоянии и об охране окружающей среды Саратовской области в 2013 году». Саратов, 2014. 244 c.

20. Безуглая Э.Ю., Воробьева И.А., Полуэктова М.В. Исследование химических процессов в атмосфере по данным мониторинга в городах // Труды главной геофизической обсерватории им. А.И. Воейкова, № 561. 2010. С. 164-184.

21. Ануфриева А.Ф., Смирнова И.В. Влияние аномальных погодных условий на формирование уровня загрязнения атмосферного воздуха в городах России // Труды главной геофизической обсерватории им. А.И. Воейкова. № $566 . \quad$ 2012. С. 246-256.

\title{
ESTIMATION OF AIR POLLUTION INFLUENCE ON DEMOGRAPHIC AND HEALTH OF THE POPULATION OF SARATOV
}

(C) 2016

N.V. Tochilkina, senior lecturer of Private Law and Environmental Security Department Saratov Institute of Social Sciences and Economics of Plekhanov Russian University of Economics, Saratov (Russia)

Abstract. The article examines the impact of air pollution on the demographic characteristics of the residents of Saratov. It describes the main air pollutants that have a significant impact on the incidence of non-communicable diseases and child mortality. The author discusses the impact of complex index of air pollution and its components on overall mortality rates, mortality from cancer, respiratory diseases and the mortality rate of children under one year. The research has shown that there is a strong direct relationship between the complex index of air pollution and mortality from respiratory diseases and infant mortality rates. The author also reveals that the total mortality rate is closely associated with the increased content in the air of nitrogen oxide, the mortality rate from cancer with the increased content of nitrogen oxide and phenol, the mortality rate from respiratory diseases with excess of formaldehyde, the mortality rate of children under one year - with excess of formaldehyde and phenol. Despite the importance and relevance of such studies the author notes that it is difficult to access the information about morbidity by classes of diseases, by age and sex of the inhabitants of various administrative areas of the city. It does not enable a full analysis of the current situation and retrospective studies for its prediction.

Keywords: air pollution; comprehensive indicator of air pollution level; overall mortality level; mortality from respiratory diseases; mortality rate from cancer; infant mortality; Saratov.

УДК 552.12

\section{ЭКОЛОГО-ТАКСОНОМИЧЕСКИЙ АНАЛИЗ ПЕТРОФИЛЬНОЙ ФЛОРЫ ОКРЕСТНОСТЕЙ СЕЛА ИХРЕК РУТУЛЬСКОГО РАЙОНА РЕСПУБЛИКИ ДАГЕСТАН} (C) 2016

А.М. Халидов, кандидат биологических наук, доцент кафедры ботаники Дагестанский государственный университет, Махачкала (Россия)

Аннотация. Изучение петрофитов как своеобразной группы растений, приуроченной к каменистым субстратам, важно для познания истории флоры и природы в целом. Их экологические особенности, таксономический состав, географо-генетические связи и другие характеристики несут в себе информацию об этапах становления горной страны и ее флоры. Рутульский район входит в состав Высокогорного сланцевого Дагестана и граничит на юге с Республикой Азербайджан, на востоке с Ахтынским и Курахским районами, на северозападе с Тляратинским и Чародинским районами, на севере с Кулинским, Агульским и Лакским районами Рес- 
Халидов А.М.

публики Дагестан. Для рельефа Высокогорного Дагестана характерна большая крутизна склонов, скалистость и каменистость гор, в пределах которого и находится район наших исследований. В данной статье проведены таксономический, биоморфный, экологический анализы петрофильных комплексов исследованного района. Также проведен анализ эндемизма и реликтовости флоры петрофильных комплексов. По сборам гербарного материала выявлены доминирующие семейства, роды и виды петрофильных комплексов данного района. Изучены биоморфные и экологические группы петрофильных комплексов. Установлена приуроченность петрофитов к различным экологическим условиям. Выявлены эндемичные, реликтовые и охраняемые виды петрофильных комплексов. Определены перспективы для оценки состава флоры данного региона и ее динамики.

Ключевые слова: флора; петрофиты; семейство; род; вид; хасмофиты; гляреофиты; индифферентные петрофиты; фанерофиты; хамефиты; гемикриптофиты; криптофиты; терофиты; эндемики; реликты; палеоэндемики; краснокнижные виды; республика Дагестан; Рутульский район; село Ихрек.

В окрестностях с. Ихрек Рутульского района республики Дагестан нами выявлено 126 видов высших сосудистых растений, относящихся к 97 родам и 34 семействам. Видовой состав флоры петрофитов относится к трем отделам: Polipodiophyta - 5видов $(3,9 \%)$ от общего числа видов, Pinophyata - 2 (1,6\%), Magnoliophyta- 119 (94,4\%). Из последних к классу Liliopsida относятся 8 видов $(6,3 \%)$, к Magnoliopsida - 111 $(88,1 \%)[4$, c. $747 ; 5$, с. $328 ;$ c. $352 ;$ c. 320$]$.

Таксономический анализ петрофильной флоры показал, что в ней доминируют семейства: Asteraceae 17 видов $(13,5 \%)$ от общего числа видов, Caryophyllaceae - $11(8,3 \%)$, Lamiaceae - $10(7,9 \%)$, Brassicaceae - 8 (6,3\%), Rosaceae - 7 (5,5\%), Fabaceae - 6 (4,7\%), Poaceae - 6 (4,7\%), Campanulaceae - 5 (3,9\%), Apiaceae - 5 (3,9\%); Scrophulariaceae - 5 (3,9\%) (табл. 1).

Таблица 1 - Доминирующие семейства флоры

\begin{tabular}{|c|c|c|c|}
\hline № & Семейства & $\begin{array}{l}\text { Число } \\
\text { видов }\end{array}$ & $\begin{array}{l}\text { \% от общего } \\
\text { числа видов }\end{array}$ \\
\hline 1 & Asteraceae & 17 & 13,5 \\
\hline 2 & Caryophyllaceae & 11 & 8,3 \\
\hline 3 & Lamiaceae & 10 & 7,9 \\
\hline 4 & Brassicaceae & 8 & 6,3 \\
\hline 5 & Rosaceae & 7 & 5,5 \\
\hline 6 & Fabaceae & 6 & 4,7 \\
\hline 7 & Poaceae & 6 & 4,7 \\
\hline 8 & Campanulaceae & 5 & 3,9 \\
\hline 9 & Apiaceae & 5 & 3,9 \\
\hline 10 & Scrophulariaceae & 5 & 3,9 \\
\hline & Всего & 80 & 63,5 \\
\hline
\end{tabular}

Таким образом, эти семейства входят в ведущие семейства и принимают активное участие в формировании петрофильных флор и других регионов.

Семейств с 3-4 видами насчитывается в данной флоре 7. К ним относятся Boraginaceae - $4(3,2 \%)$, Crassulaceae - $4(3,2 \%)$, Ranunculaceae - $3(2,4 \%)$, Polygonaceae $-3(2,4 \%)$, Saxifragaceae $-3(2,4 \%)$, Primulaceae $-3(2,4 \%)$, Rubiaceae $-3(2,4 \%)$.

Семейств с 2 видами -6 , что составляют суммарно 9,5\%. Таковыми являются семейства Aspleniaceae, Aspidiaceae, Cupressaceae, Alliaceae, Chenopodiaceae и Valerianaceae.

Остальные 11 семейств или $8,7 \%$ содержат в своем составе по 1 виду. Это такие семейства как Polypodiaceae, Urticaceae, Papaveraceae, Geraniaceae, Gentianaceae, Onagraceae, Rhamnaceae, Violaceae, Cistaceae, Paeoniaceae, Asclepiadaceae.

Среди родов преобладают 6 родов $(6,2 \%)$ от общего числа родов, которые содержат в своем составе 3 и более видов. Это Campanula - 5видов (3,9\%) от обще- го числа видов флоры, Anthemis - 3 (2,4\%), Sedum - 3 $(2,4 \%)$, Scrophularia - $3(2,4 \%)$, Cerastium - $3(2,4 \%)$, Saxifraga-3 (2,4\%) (табл. 2).

Таблица 2 - Доминирующие роды флоры

\begin{tabular}{|c|c|c|c|}
\hline № & Роды & Число видов & $\begin{array}{l}\text { \% от общего } \\
\text { числа видов }\end{array}$ \\
\hline 1 & Campanula & 5 & 3,9 \\
\hline 2 & Anthemis & 3 & 2,4 \\
\hline 3 & Sedum & 3 & 2,4 \\
\hline 4 & Scrophularia & 3 & 2,4 \\
\hline 5 & Cerastium & 3 & 2,4 \\
\hline 6 & Saxifraga & 3 & 2,4 \\
\hline & Всего & 20 & 15,9 \\
\hline
\end{tabular}

Роды с 2 видами 15, что составляют суммарно 23,8\%. В их состав входят Asplenium, Juniperus, Woodsia, Allium, Silene, Thalictrum, Draba, Astragalus, Primula, Thymus, Papaver, Galium и др.

Роды с 1 видом составляют 60,3\% или 76 видов. Таковыми являются Nepeta, Pyrethrum, Artemisia, Psephellus, Salvia, Lamium, Onosma, Bupleurum, Vicia и др.

Среди родов монотипными являются Eunomia, Murbeckiella, Dryas, Acanthophaca, Symphyoloma u Pseudobetckea, которые составляют 6,2\% от общего числа родов.

Биоморфный анализ петрофильной флоры района исследования проведен по системе жизненных форм К. Раункиера [3, с. 176], которая позволяет классифицировать растения в зависимости от расположения почек возобновления.

Первое место занимают гемикриптофиты (Hk) 93 вида (73,8\%) (табл. 3). Состав видов Rumex scutatus L., Minuartia biebersteinii (Rupr.) Schischk., Arenaria lychnidea Bieb., Thalictrum foetidum L., Alchemillia sericea Willd., Saxifraga juniperifolia Adams, Lamium tomentosum Willd., Veronica petraea (Bieb.) Stev., Artemisia daghestanica Krasch. et A. Poretzky, Campanula alliariifolia Willd., Astragalus humilis Bieb., Potentilla multifida L., Cirsium sinuatum (Trautv.) Boiss. и др. Эти жизненные формы наиболее устойчивы при освоении каменистых субстратов, среди которых преобладают стержнекорневые многолетники класса двудольных.

Таблица 3 - Биоморфный состав флоры

\begin{tabular}{|l|c|c|c|c|c|}
\hline \multicolumn{1}{|c|}{ Биоморфы } & $\mathrm{Ph}$ & $\mathrm{Ch}$ & $\mathrm{Hk}$ & $\mathrm{Kr}$ & $\mathrm{Th}$ \\
\hline Число видов & 7 & 11 & 93 & 9 & 7 \\
\hline \% от общего числа & 5,5 & 8,7 & 73,8 & 7,1 & 5,5 \\
\hline
\end{tabular}

На втором месте находятся хамефиты $(\mathrm{Ch})-11$ $(8,7 \%)$. К ним относятся растения с отмирающими на зиму верхушечками побегов, а почки возобновления у 
них расположены ближе к поверхности почвы и на зиму прикрываются снегом. Видовой состав: Thymus nummularius Bieb., Th. daghestanicus Klock. et Shost., Dryas caucasica Juz., Onosma caucasica Levinet M. Pop., Ziziphora serpyllacea Bieb., Paederotella daghestanica (Trautv.) Kem.-Nath., Anthemis iberica Bieb., Scutellaria daghestanica Grossh., Draba bryoides DC., D. siliquosa Bieb., Silene daghestanica Rupr. и др.

C незначительной разницей представлены криптофиты $(\mathrm{Kr})-9(7,1 \%)$, среди которых преобладают корневищные и луковичные виды. К ним относятся Allium oreophilum C.A. Mey., A. samurense Tscholok., Ranunculus arachnoideus C.A. Mey., Eunomia rotundifolia C.A. Mey., Chamerion dodonaei (Vill.) Holub, Astrodaucus orientalis (L.) Drude, Chaerophyllum humile Stev., Symphyoloma graveolens C.A. Mey., Cerinthe caucasica (Hc.) Galuschko.

Фанерофиты (Ph) содержат 7 видов (5,5\%), которые представлены исключительно кустарниковыми и кустарничковыми формами, отличающимся высотой побегов. Состав Juniperus sabina L., J. oblonga Bieb., Sorbus fedorovii Zaikonn, Spiraea hypericifolia L., Rosa pulverulenta Bieb., Acanthophaca beckerana (Traut.) Galushko, Rhamnus pallasii Fisch. et C.A. Mey.

Терофиты (Th) включают также 7 видов (5,5\%), которые чаще поселяются на осыпях и в трещинах скал. Это Saxifraga tridactylites L., Papaver caucasicum Bieb. Sobolewskia truncate N. Busch., Sedum pilosum Bieb., Nonea alpestris (Stev.) G. Don., Pseudobetckea caucasica (Boiss.) Lincz., Senecio sosnovskyi Sof.

Петрофиты исследуемого района по их приуроченности к тому или иному субстрату можно разделить на следующие экологические группы: хасмофиты - виды, обитающие на скалах; гляреофиты - виды, обитающие на осыпях и других субстратах с близкими к ним экологическими условиями; индифферентные петрофиты - виды, неизбирательные к состоянию субстрата, т.е. одинаково успешно осваивающие экологически разнотипные формы обнаженного рельефа $[4$, с. $296 ; 5$, с. $76-77 ; 6$, с. $26 ; 7$, с. 21$]$.

В петрофильной флоре района в абсолютном большинстве представлены индифферентные петрофиты - 58 видов (40,0\%). К ним относятся Juniperus sabina L., Poa glauca Vahl, Fl. Dan., Cerastium daghestanicum Schischk., Arenaria lychnidea Bieb., Alchemillia sericea Willd., Potentilla multifida L., Oxytropis cyanea Bieb., Cerinthe caucasica (Hc.) Galuschko, Ziziphora serpyllacea Bieb., Astrodaucus orientalis (L.) Drude, Astragalus humilis Bieb., Aster alpines L., Leontodon asperrimus (Willd.) Ball, Taraxacum confusum Schischk., Anthemis marschalliana Willd. и др. (табл. 4). Гляреофиты составляют 30,2\% или 38 видов. Состав: Rumex scutatus L., Chenopodium foliosum Aschers., Paeonia mlokosewitschii Lomak., Ranunculus arachnoideus C.A. Mey., Sedum stevenianum Rouyet Camus, Rosa pulverulenta Bieb., Chaerophyllum humile Stev., Lamium tomentosum Willd., Betonica nivea Stev., Pseudobetckea caucasica (Boiss.) Lincz., Cirsium sinuatum (Trautv.) Boiss., Artemisia daghestanica Krasch. et A. Poretzky и др. Хасмофиты содержат в своем составе 30 видов (23,8\%): Woodsia alpina (Balton) S.F. Gray, Asplenium ruta-muraria L., Allium samurense Tscholok., Gypsophila tenuifolia Bieb., Alyssum daghestanicum Rupr., Arabis mollis Stev., Saxifraga juniperifolia Adams,
Sempervivum caucasica Rupr. ex Boiss., Erodium fumarioides Stev., Scrophularia rupestris Bieb. ex Willd., Campanula argunensis Rupr., Kemulariella rosea (Stev. ex Bieb.) Tamamsch. и др.

Таблица 4 - Экологический состав флоры

\begin{tabular}{|c|l|c|c|}
\hline № & \multicolumn{1}{|c|}{$\begin{array}{c}\text { Экологическая } \\
\text { группа петрофитов }\end{array}$} & $\begin{array}{c}\text { Число } \\
\text { видов }\end{array}$ & $\begin{array}{c}\text { № от общего } \\
\text { числа }\end{array}$ \\
\hline 1 & Индифферентные & 58 & 46,0 \\
\hline 2 & Гляреофиты & 38 & 30,2 \\
\hline 3 & Хасмофиты & 32 & 23,8 \\
\hline & Всего & 126 & 100 \\
\hline
\end{tabular}

Таким образом, петрофильная флора района исследования представлена в большей степени индифферентными петрофитами, так как преобладают разнотипные формы обнаженного рельефа.

Среди петрофильных комплексов района исследования выявлено 70 видов растений или 55,5\% от общего числа, которые имеют статус [8, с. 329 ; 9, с. 96 ; 10, с. 1801-1804].

Из эндемичных видов преобладают эндемики Кавказа (ЭК) - 26 видов (20,3\%) от числа эндемиков. К ним относятся Woodsia fragilis (Trev.) Moore, Arenaria lychnidea Bieb., Draba bryoides DC., Eunomia rotundifolia C.A. Mey., Sedum stevenianum Rouyet Camus, Oxytropis cyanea Bieb., Astragalus oreades C.A. Mey., Viola minuta Bieb., Chaerophyllum humile Stev., Primula farinifolia Rupr., Thymus nummularius Bieb., Nepeta cyanea Stev., Galium brachyphyllum Roem. et Schult.,Campanula argunensis Rupr., Anthemis iberica Bieb., Senecio sosnovskyi Sof., Taraxacum confusum Schischk. и др. Эндемики Дагестана (ЭД) представлены 14 видами $(11,1 \%)$. Видовой состав Stipa daghestanica Grossh., Cerastium multiflorum C.A. Mey., Dianthus daghestanicus Charadze, Sobolewskia truncata N. Busch., Nonea alpestris (Stev.) G. Don., Thymus daghestanicus Klock. et Shost., Asperula glomerata (Bieb.) Griseb., Artemisia daghestanica Krasch. et A. Poretzky и др. Эндемики Дагестана и Восточного Закавказья (ЭВ3) содержат в своем составе 7 видов (5,5\%). Состав: Silene daghestanica Rupr., Ranunculus arachnoideus C.A. Mey., Gentiana lagodechiana (Kusn.) Grossh., Veronica petraea (Bieb.) Stev., Pyrethrum silaifolium Stev., Kemulariella rosea (Stev. ex Bieb.) Tamamsch. и Scorzonera filifolia Boiss. Эндемики Большого Кавказа (ЭБК) включают 6 видов (4,8\%). Это такие виды как, Allium oreophilum C.A. Mey., Minuartia biebersteinii (Rupr.) Schischk., Sedum involucratum Bieb., Gypsophila tenuifolia Bieb., Campanula. petrophila Rupr. и Cirsium sinuatum (Trautv.) Boiss. Эндемики Восточного Кавказа содержат 5 видов (3,9\%): Calamagrostis caucasicus Trin., Vicia semiglabra Rupr. ex Boiss., Betonica nivea Stev., Pseudobetckea caucasica (Boiss.) Lincz. и Campanula kolenatiana C.A. Mey., ex Rupr. Эндемики ЮжногоДагестана (ЭД) - 4 (3,2\%): Allium samurense Tscholok., Cerastium daghestanicum Schischk., Acanthophaca beckerana (Traut.) Galushko и Scutellaria daghestanica Grossh. Эндемики Восточного Закавказья 3 вида (2,4\%): Paeonia mlokosewitschii Lomak., Heracleum grandiflorum Stev. ex Bieb. и Campanula caucasica Bieb. Реликтами являются 6 видов (суммарно 
4,8\%). Из них 3 являются третичными (Rt), и 3 реликтами (Rc) ледниковой эпохи (соответственно Asplenium ruta-muraria L., Dryas caucasica Jus., Androsace barbulata Ovcz., Erodium fumarioides Stev., Rhamnus pallasii Fisch. et C.A. Mey., Helianthemum nummularium (L.) Mill.). Палеоэндемики (ПЭ) представлены 7 видами (5,5\%). Это Silene daghestanica Rupr., Alyssum daghestanicum Rupr., Vicia semiglabra Rupr., ex Boiss., Acanthophaca beckerana (Traut.) Galushko, Pseudobetckea caucasica (Boiss.) Lincz., Paederotella daghestanica (Trautv.) Kem.-Nath. и Campanula caucasica Bieb. Краснокнижными (Кр) являются 9 видов (7,1\%): Woodsia fragilis (Trev.) T. Moore, Allium oreophilum C.A. Mey., Paeonia mlokosewitschii Lomak., Papaver paucifoliatum (Traut.) Fedde, Gentiana lagodechiana (Kusn.) Grossh. и др. (табл. 5).

Таблица 5 - Статус видов флоры

\begin{tabular}{|c|c|c|c|c|c|c|c|c|c|c|c|}
\hline Статус & $\ddot{\sim}$ & $\ddot{\mathscr{z}}$ & $\begin{array}{c}m \\
\tilde{n}\end{array}$ & $\frac{\mathscr{c}}{\Omega}$ & $\frac{4}{\Omega}$ & $\frac{s}{m}$ & กี & $\frac{\mathbb{2}}{0}$ & $\tilde{n}$ & से & $\mathcal{\theta}$ \\
\hline $\begin{array}{l}\text { Число } \\
\text { видов }\end{array}$ & 3 & 3 & 7 & 26 & 6 & 5 & 14 & 4 & 3 & 9 & 7 \\
\hline $\begin{array}{l}\% \\
\text { от числа } \\
\text { эндемиков }\end{array}$ & 2,4 & 2,4 & 5,5 & 20,3 & 4,8 & 3,9 & 11,1 & 3,2 & 2,4 & 7,1 & 5,5 \\
\hline
\end{tabular}

Таким образом, в формировании петрофильной флоры исследованного района в абсолютном большинстве участие принимают эндемики Кавказского и Дагестанского корня.

\section{СПИСОК ЛИТЕРАТУРЫ:}

1. Гроссгейм А.А. Определитель растений Кавказа. М.: Советская наука, 1949. 747 с.

2. Галушко А.И. Флора Северного Кавказа. Определитель в 3 т. Ростов-на-Дону: Изд-во РГУ, 19781980. Т. 1.328 c., Т. 2.352 c., Т. 3.320 c.

3. Raunkiaer C. Life forms of plants and statistical Plant geography. N.Y. Landon, 1934. S. 176.

4. Шихэмиров М.Г. Результаты анализа флоры Самурской долины Дагестана от моста Цахул до верховий Самура Изв. АН Азерб. ССР. 1970. № 4. С. 296.

5. Шхагапсоев С.X. К охране скально-осыпной растительности Кабардино-Балкарии. Редкие и исчезающие виды растений и животных, флористические и фаунистические комплексы Северного Кавказа, нуждающиеся в охране: Тез. докл. научн.- практ. конф. Ставрополь: СГПИ. 1986. С. 76-77.

6. Теймуров А.А. Эколого-географическая и биологическая характеристика петрофитов Самурского хребта и Джуфудага в связи с историей формирования флоры Южного Дагестана: автореферат дис...канд. биол. наук. Махачкала: ДГУ, 1998. 26 с.

7. Халидов А.М. Петрофиты Транссамурских высокогорий Южного Дагестана и их анализ: автореф. дис... канд. биол. наук. Махачкала: ДГУ, 2006. 24 с.

8. Красная книга республики Дагестан (растения) / отв. Г.М. Абдурахманов. Махачкала, 1998. 329 с.

9. Аджиева А.И. Кавказские эндемичные виды растений на территории Дагестана. Махачкала, 2008. $96 \mathrm{c}$.

10. Муртузалиев Р.А., Алиев Х.У. О некоторых новых и редких видах флоры Дагестана // Ботанический журнал. 2008. Т. 93. С. 1801-1804.

\section{ECOLOGICAL-TAXONOMIC ANALYSIS OF THE PETROPHYTE FLORA OF IKHREK (RUTULSKY DISTRICT) SURROUNDINGS OF REPUBLIC OF DAGESTAN} (C) 2016

A.M. Khalidov, candidate of biological sciences, associate professor of Botanic Department Dagestan State University, Makhachkala (Russia)

Abstract. The study of petrophytes, as a peculiar group of plants, is important for understanding the history of the flora and nature in general. Their ecological characteristics, taxonomic composition, geographic and genetic relationships and other characteristics carry information about the stages of development of the mountain country and its flora. Rutulsky district is a part of Highland Dagestan and borders on the Republic of Azerbaijan in the South, Akhtynsky and Kurakhsky districts in the East, Tlyaratinsky and Charodinsky districts in the North-West, Kulinsky, Agulsky and Laksky districts of the Republic of Dagestan in the North. The relief of Highland Dagestan, which is the area of our research, is characterized by a large slope, stony and rocky mountains. The following paper contains taxonomic, biomorphic, ecological analyses of petrophyte complexes of the studied area and an analysis of endemism and relict flora of petrophytic complexes. Herbarium material has helped to find the dominant family, genera and species of petrophyte complexes of the area. Biomorphic and environmental groups of petrophyte complexes have been studied. Confinement of petrophytes to different environmental conditions has been established. Endemic, relict and protected species of petrophyte complexes have been identified.

Keywords: flora; petrophyte; family; genus; species; chasmophyte; parafita; indifferent; phanerophyte; halfeti; hemicryptophytes; cryptophyta; tiropita; endemics; relicts; paleoendemic; red-listed species; republic of Dagestan; Rutulsky District; Ikhrek. 